\title{
ОСОБЕННОСТИ МЕЖДИСЦИПЛИНАРНЫХ ИССЛЕДОВАНИЙ В ИСТОРИИ ПСИХОЛОГИИ В УСЛОВИЯХ СТАНДАРТИЗАЦИИ ВЫСШЕГО ОБРАЗОВАНИЯ
}

\author{
И. С. Алексеенко \\ Московский гуманитарный университет
}

\begin{abstract}
Аннотация: В статье анализируются особенности развития истории психологии в современных условиях развития высшего образования. Характеризуется влияние стандартизации высшего образования на организацию и содержание историко-психологических исследований. Анализируется междисциплинарный характер историко-психологических исследований в условиях обновления образовательных стандартов. По материалам научного доклада на конференции «Кросс-культурные и междисциплинарные исследования в истории психологии: результаты и перспективы» (Москва, 24-25 ноября 2018 г.), проведенной в рамках проекта № 18513-18017, поддержанного РФФИ.

Ключевые слова: прогнозирование; прикладная психология; история психологии; мир профессий; профессиональные задачи; Атлас новых профессий
\end{abstract}

\section{PECULIARITIES OF INTERDISCIPLINARY RESEARCH IN THE HISTORY OF PSYCHOLOGY IN THE CONTEXT OF STANDARDIZATION OF HIGHER EDUCATION}

\author{
I. S. Alekseyenko \\ Moscow University for the Humanities
}

Abstract: The article analyzes the peculiarities of development of the history of psychology within the modern context of development of higher education. The author describes the influence of the standardization of higher education on the organization and content of historical and psychological research. She analyzes the interdisciplinary nature of historical and psychological research in the context of updating educational standards.

The research is based on the materials of the scientific report at the conference "Cross-Cultural and Interdisciplinary Studies into the History of Psychology: Results and Prospects" (Moscow, 2425 November 2018), held within the project No. 18-513-18017 supported by RFBR.

Keywords: history of psychology; state educational standard of higher education; federal state standard of higher education; teaching the history of psychology

Ведущей тенденцией современных научных исследований является стремление к синтезу любого знания. Тем более, что в современных условиях перехода на новые образовательные стандарты высшего образования, когда основным принципом становится переход от дисциплинарной структуры образовательного процесса к компетентностному, роль междисциплинарных исследований еще больше возрастает. 
Процесс стандартизации высшего образования воспринимается научным и педагогическим сообществом неоднозначно. Образовательный стандарт определяет содержание, требования и объемы к подготовке выпускников и является основой объективной оценки уровня образования. Казалось бы, что любое упорядочивание и организация образовательного процесса в соответствии с определенными нормами и правилами должны привести к усовершенствованию и повышению качества образования. Но ли приводит ли? Или, наоборот, влечет за собой некую шаблонность, инертность, несамостоятельность.

История психологии, являющаяся научной дисциплиной, способной не только объективно сохранить и воспроизвести знания, накопленные в ходе исторического развития психологической науки, но и предвидеть ее дальнейшее развитие, в этом смысле не является исключением. Значение таких исследований важно с точки зрения научного труда любого уровня и любой тематики, будь курсовая, выпускная квалификационная работа, магистерская или кандидатская диссертация, статья, ведь приступая к изучению той или иной проблемы, мы всегда обращаемся к истории ее разработки и опираемся на ее междисциплинарность.

Д. Шульц и С. Шульц, говоря о «влиянии истории психологии на психологию в целом», проводят аналогию, как «прошлое науки самым непосредственным образом воздействует на ее настоящее. Например, психологи, изучающие поведение, также признают влияние прошлого на настоящее. Они полагают, что поведение определяется предшествующими условиями жизни и укоренившимся опытом - иными словами, текущее состояние человека можно объяснить прошлым» (Шульц Д., Шульц С. 1998: 15).

С другой стороны, исследования историко-психологического характера достаточно сложны. Любое историческое событие, описываемое учеными, уже свершилось. Историки психологии, имеющие определенный познавательный опыт, свое мировоззрение, свою точку зрения, должны непредвзято и честно воссоздать историю в инвариантности, по возможности игнорируя субъективную оценку происходящего. Также стоит отметить, проблемы, возникающие в процессе историко-психологических исследований, обусловлены и сменой философско-методологических основ науки, произошедшей в 90-годы прошлого века. Это влечет за собой переоценку историко-психологических событий и роли исторических личностей в них.

Таким образом, с одной стороны важность, а с другой стороны сложность историко-психологических исследований определяет специфику ее междисциплинарного характера.

Методика преподавания дисциплины «История психологии» самым непосредственным образом реагирует на изменения, происходящие как в са- 
Научные труды Московского гуманитарного университета 2019 № 1

мой науке (смена философско-методических основ), так и в системе высшего образования.

Уже в первых «Требованиях к минимуму содержания и уровню подготовки выпускника по специальности 020400 - Психология» 1996 г. значилось, что выпускник должен «знать историю становления и развития психологической науки» (Государственный образовательный стандарт, 1996: Электр. ресурс) и определялось, что дисциплина изучение дисциплины «История психологии» является обязательной. Были достаточно четко прописаны дидактические единицы, которые должен освоить студент при изучении дисциплины. С появлением первого образовательного стандарта по специальности «Психология» с присвоением квалификации выпускникам «Психолог. Преподаватель психологии» в 2000 г., место дисциплины «История психологии» определилось в базовой части общепрофессионального цикла и на ее освоение отводилось достаточно большое количество часов - 180 часов. Согласно учебному плану, она изучалась в течение двух семестров на третьем курсе (для очной формы обучения) и на четвертом курсе (для студентов вечерней формы обучения). Дидактические единицы, которые должен был освоить студент при изучении дисциплины также были определены четко (Государственный образовательный стандарт, 2000: Электронный ресурс). По данному образовательному стандарту обучались студенты специальности «Психология», принятые на обучение с 2000 по 2011 г.

В связи с присоединением России к Болонскому процессу, в 2009 г. появляются новое третье поколение федеральных государственных образовательных стандартов бакалавров и магистров по направлениям подготовки «Психология», где дидактические единицы были заменены компетенциями. Стандарт бакалавра тогда еще содержал дисциплину «История психология» в качестве обязательной. Студенты, обучающиеся по данному стандарту, должны были знать «психологические феномены, категории методы... с позиции существующих в отечественной и зарубежной науке подходов», уметь «анализировать психологические теории...», а также в рамках научно-исследовательской деятельности изучать отечественный и зарубежный опыт по тематике исследований. (Федеральный государственный образовательный стандарт, 2011: Электронный ресурс). Новый же стандарт направлений подготовки бакалавра «Психолого-педагогическое образование» вообще исключил дисциплину «История психология» из учебного плана.

В виду вступления в силу Федерального Закона «Об образовании в Российской Федерации» от 29 декабря 2012 г. № 273, федеральный государственный образовательный стандарт по направлению «Психология» был вновь обновлен и исключил компетенции, напрямую связанные с дисциплиной «История психологии», тем самых поставив угрозу исключения 
дисциплины из учебного плана. Но тем самым предопределил значение междисцплинарного подхода. В связи с тем, что формирование основных компонентов компетенций невозможно в рамках одной дисциплины. Возникает необходимость в рамках изучения истории психологии установления междисциплинарных связей.

Впереди вступление еще одной обновленной версии образовательного стандарта на основе профессиональных стандартов. Так что будущее дисциплины «История психологии» не определено. Таким образом, в связи с введением стандартов третьего поколения история психологии как учебная дисциплина претерпевает определенную трансформацию. Об этом говорит хотя бы тот факт, что если раньше дисциплина изучалась студентами в объеме 180 часов в течение двух семестров, то на сегодняшний день ее объем составляет лишь 108 часов в течение одного семестра.

Естественно, что существуют проблемы, возникающие в процессе преподавания дисциплин историко-психологического цикла, связанных и со сложностью восприятия дисциплины обучающимися и ее междисциплинарным характером. Так, изучение дисциплины «История психологии» требует обращения к первоисточникам, а студенты, имея возможность быстрого и легкого получения информации любого характера через Интернет, не обращаются к таковым. И здесь важно выстроить траектории междисплинарных связей дисциплины «История психологии» с другими дисциплинами, входящими в основные профессиональные образовательные программы.

Таким образом, характеризуя особенности развития историко-психологических исследования в условиях стандартизации высшего образования, можно отметить ее главную роль и первостепенное значение в установлении междисциплинарных связей между всеми элементами основных профессиональных образовательных программ высшего образования.

\section{СПИСОК ЛИТЕРАТУРЫ}

Государственный образовательный стандарт высшего профессионального образования. Государственные требования к минимуму содержания и уровню подготовки выпускника по специальности 020400 - Психология (1996) [Электронный ресурс] // Портал Федеральных государственных образовательных стандартов высшего образования. URL: http://fgosvo.ru/ archivegosvpo/156/155/3/156 (дата обращения 12.01.2018).

Государственный образовательный стандарт высшего профессионального образования Специальность 020400 «Психология» Квалификация Психолог. Преподаватель психологии (2000) // Портал Федеральных государственных образовательных стандартов высшего образования. URL: http:// fgosvo.ru/archivegosvpo/157/155/6/711 (дата обращения 12.01.2018). 
Федеральный государственный образовательный стандарт высшего профессионального образования по направлению подготовки 030300 Психология. (2011) [Электронный ресурс] // Портал Федеральных государственных образовательных стандартов высшего образования. URL: http://fgosvo. $\mathrm{ru}$ /fgosvpo/7/6/1/3(дата обращения 12.01.2018).

Шульц, Д., Шульц. С. Э. (1998) История современной психологии. СПб. : Издательство «Речь». 532 с.

Дата поступления: 12.01.2018 2.

Алексеенко Ирина Сергеевна - кандидат психологических наук, доцент кафедры общей психологии и истории психологии Московского гуманитарного университета. Адрес: 111395, Россия, г. Москва, ул. Юности, д. 5. Тел.: +7 (499) 374-70-34, +7 (916) 796-81-58. Эл. адрес: ialexeenko@mail.ru

Alekseenko Irina Sergeevna, Candidate of Psychology, Associate Professor, Department of General Psychology and History of Psychology, Moscow University for the Humanities. Postal address: 5, Yunosti St., Moscow, Russian Federation, 111395. Tel.: + 7 (499) 374-70-34, +7 (916) 796-81-58. E-mail: ialexeenko@ mail.ru

\section{Для цитирования:}

Алексеенко И. С. Особенности междисциплинарных исследований в истории психологии в условиях стандартизации высшего образования [Электронный ресурс] // Научные труды Московского гуманитарного университета. 2019. № 1. URL: http://journals.mosgu. ru/trudy/article/view/936 (дата обращения: дд.мм.гг.). DOI: 10.17805/trudy.2019.1.9 